\title{
СИМУЛЯЦИОННЫЕ ТЕХНОЛОГИИ КАК ПРОДУЦЕНТЫ КАЧЕСТВЕННО НОВЫХ СВОЙСТВ СОДЕРЖАТЕЛЬНОЙ ЧАСТИ МЕДИЦИНСКОГО ОБРАЗОВАНИЯ
}

\section{SIMULATION TECHNOLOGIES AS \\ PRODUCERS OF QUALITATIVELY NEW PROPERTIES OF THE CONTENT OF MEDICAL EDUCATION}

L. Gatiyatullina A. Tazieva

Summary: Background: The relevance and effectiveness of the use of simulation technologies in medical education is due to the fact that they can improve the quality of specialist training and ensure the verification of acquired competencies before using them in reality. An important element in achieving the effect of psychological presence in the educational process is the concept of embodied consciousness, which explains the fact that students perceive information better when performing actions, and not when they watch others perform it, or listen to it, or read about it. Simulation technologies produce qualitatively new properties of the content of education, which were not present in traditional methods of teaching physicians.

The aim of the study is to conceptually substantiate the urgency of practical implementation of the pedagogical conditions necessary for the positive dynamics of the formation of professional competence in future doctors by simulation technologies of mixed reality in higher education institutions.

Methods: analysis and synthesis, comparison, abstraction and concretization, generalization, formalization, induction and deduction, idealization, analogy, modeling, thought experiment.

Results: in the process of learning, the authors describe the educational simulation as a structured scenario with a detailed system of rules, tasks and strategies that are created with a very specific goal: to form specific competencies that can be directly transferred to the real world on the patient. In the simulation lesson, the priority is precisely the educational task, in the process of which a safe negative result is assumed in order to be able to feel the measure of their responsibility and achieve a positive result in their future professional activities.

Conclusion: compared with traditional forms of learning and simulation, the peculiarities of formation of professional competence of future physicians, the proposed structural model of the center of simulation technologies in medical school, argued its necessity.

Keywords: simulation training, medical education, professional competence, structural model.
Гатиятуллина Лилия Лукмановна

преподаватель, ассистент, Казанский государственный медицинский университет lilijaluk@yandex.ru

Тазиева Алия Фархатовна Казанский государственный медицинский университет tazieva.alila@mail.ru

Аннотация: Обоснование: Актуальность и эффективность использования симуляционных технологий в медицинском образовании связаны с тем, что они позволяют повысить качество подготовки будущего специалиста и обеспечить проверку приобретенных компетенций перед их использованием в реальности. Важным элементом достижения эффекта психологического присутствия в образовательном процессе является концепция воплощенного сознания, которая объясняет тот факт, что учащиеся лучше воспринимают информацию при выполнении действий, а не тогда, когда наблюдают за тем, как это выполняют другие, или слушают, или читают об этом. Симуляционные технологии продуцируют качественно новые свойства содержательной части образования, которых ранее не было в традиционных методах обучения медиков.

Цель исследования: концептуально обосновать насущность практической реализации педагогических условий, необходимых для положительной динамики формирования профессиональной компетентности у будущих врачей посредством симуляционных технологий смешанной реальности в учреждениях высшего образования.

Методы: анализ и синтез, сравнение, абстрагирование и конкретизация, обобщение, формализация, индукция и дедукция, идеализация, аналогия, моделирование, мысленный эксперимент.

Результаты: образовательную симуляцию авторы статьи описывают как структурированный сценарий с детально разработанной системой правил, заданий и стратегий, которые созданы с совершенно определенной целью: сформировать специфические компетенции, которые могут быть прямо перенесены в реальный мир на пациента. На симуляционном занятии приоритетом является именно учебная задача, в процессе которой предполагается безопасный отрицательный результат для того, чтобы иметь возможность прочувствовать меру своей ответственности и достичь положительного результата в будущей профессиональной деятельности.

Заключение: проведено сравнение традиционных форм обучения и симуляционных методик, исследованы особенности формирования профессиональной компетентности у будущих врачей, предложена структурная модель центра симуляционных технологий при медицинском ВУЗе, аргументирована её необходимость.

Ключевые слова: симуляционное обучение, медицинское образование, профессиональная компетентность, структурная модель.

\section{Обоснование}

переходом на новые показатели качества медицинской помощи обострились проблемы усиления практической направленности професси- онального образования, организации продуктивной самостоятельной работы студентов, интернов и врачей, что требует активного внедрения современных цифровых технологий в образовательный процесс. В системе 
высшего медицинского образования уже давно начался поиск оптимальных практикоориентированных форм обучения, целью которых является эффективное обеспечение формирования профессиональных компетентностей будущих специалистов на основе электронного, смешанного обучения, непрерывного образования, использования симуляционных технологий, тренажеров дополненной, смешанной и виртуальной реальности [2]. Актуальность и эффективность использования симуляционных технологий в медицинском образовании связана с тем, что они позволяют повысить качество подготовки специалиста и обеспечить проверку приобретенных компетенций перед их использованием в реальности. Важным элементом достижения эффекта психологического присутствия в образовательном процессе является концепция воплощенного сознания, которая объясняет тот факт, что учащиеся лучше воспринимают информацию при выполнении действий, а не тогда, когда наблюдают за тем, как это выполняют другие, или слушают, или читают об этом. Интересно мнение В.В. Селиванова о том, что современные информационные средства представления учебного материала продуцируют качественно новые свойства содержательной части образования, которых ранее не было в традиционных методах, а средства симуляции радикально преобразуют принцип наглядности, создавая сходство реальных клинических случаев путем информационного моделирования [5].

Д. Байленсон [1], профессор Стэнфордского университета, отмечает, что тренажеры в образовании - самое психологически мощное изобретение в истории человечества, и утверждает, что практически любое умение теперь может быть отработано и улучшено путем виртуального обучения.

Цель данной работы - теоретически обосновать насущность практической реализации педагогических условий, необходимых для положительной динамики формирования профессиональной компетентности у будущих врачей при помощи симуляционных технологий смешанной реальности в учреждениях высшего образования.

\section{Методы}

Анализ и синтез, сравнение, абстрагирование и конкретизация, обобщение, формализация, индукция и дедукция, идеализация, аналогия, моделирование, мысленный эксперимент.

\section{Основная часть}

Способность решать профессиональные задачи определенного класса характеризует понятие компетентности, которая имеет конкретную хронологическую определенность и может оцениваться лишь в конечной профессиональной. практической деятельности. Умение является составной частью компетентности, однако в её структуру также входят и морально-волевые качества человека, его мотивация, стремление и умение осознавать социальную значимость профессии врача.

Мы предлагаем собственное определение симуляционного метода обучения - это структурированный педагогический сценарий с детально разработанной системой правил, заданий и стратегий, которые созданы с определенной целью: сформировать специфические компетенции учащегося, которые могут быть прямо перенесены в реальный мир на пациента.

Симуляционное обучения (simulator-based training) позволяет повторять стандартные и рискованные (для пациентов) операции и доводить их выполнение до полного автоматизма складывающихся действий и навыков, а преподаватель может позволить учащимся делать ошибки в разрешенных пределах для визуализации последствий и формирования предохранительных механизмов таких ошибок в реальной профессиональной деятельности [4].

Более того, симуляционное обучение повышает мотивацию и транслирует обучение в опыт, активирует центр праксиса и вызывает интерес к обучению, а правильно спланированные симуляционные упражнения развивают критическое мышление и способность принимать клинические решения, укрепляют уверенность в своих силах и развивают навыки взаимодействия между коллегами, что в целом поддерживает положительное отношение к обучению. На симуляционном занятии приоритетом является именно учебная задача, в процессе которой предполагается безопасный отрицательный результат для того, чтобы иметь возможность почувствовать меру своей ответственности и достичь положительного результата в будущей профессиональной деятельности. Для того, чтобы понять все преимущества дополнения традиционного обучения использованием симуляционных технологий, в таблице 1 видны особенности методик обучения и их сравнение.

\section{Результаты и обсужмение}

В последнее время интерес к симуляционному медицинскому обучению в РФ значительно возрос. Появляется оборудование, открываются новые учебные центры. Чтобы в полной мере использовать потенциал симуляционного обучения, важно придерживаться эффективной методологии, наладить сотрудничество между симуляционными центрами, обеспечить надлежащую подготовку преподавателей, способных организовать учебный процесс с учетом современного опыта. По нашему мнению, принцип симуляции в медицине должен 
Таблица 1.

Сравнительная характеристика традиционного обучения и обучения и обучения с использованием симуляционных технологий

\begin{tabular}{|c|c|c|}
\hline \multirow{2}{*}{ Составляющие обучения } & \multicolumn{2}{|c|}{ Особенности технологии обучения } \\
\hline & Традиционное обучение & Симуляционных технологий смешанной реальности \\
\hline $\begin{array}{l}\text { Место и роль преподавателя в образова- } \\
\text { тельном процессе }\end{array}$ & $\begin{array}{l}\text { Преподаватель выполняет роль поставщика ин- } \\
\text { формации, определяющего все аспекты процесса } \\
\text { обучения }\end{array}$ & $\begin{array}{l}\text { Преподаватель выполняет роль диагноста, консуль- } \\
\text { танта }\end{array}$ \\
\hline $\begin{array}{l}\text { Место и роль студентов в образовательном } \\
\text { процессе }\end{array}$ & $\begin{array}{l}\text { Ориентация на деятельность преподавателя, кото- } \\
\text { рый передает знания группе студентов. }\end{array}$ & $\begin{array}{l}\text { Усвоение и генерирование информации в активной } \\
\text { работе с учебным материалом на тренажерах }\end{array}$ \\
\hline Тип информационной коммуникации & $\begin{array}{l}\text { Управляемая преподавателем. } \\
\text { Органы чувств, которые вовлечены в процесс вос- } \\
\text { приятия - зрение, слух. } \\
\text { Коммуникационные отношения - по необходимости }\end{array}$ & $\begin{array}{l}\text { Многоканальная система, которая генерирует ин- } \\
\text { формацию между преподавателем и студентами, } \\
\text { задействованы все органы восприятия и чувств. } \\
\text { Имитация коммуникационного взаимодействия в } \\
\text { конкретных профессиональных ситуациях, имитация } \\
\text { практических действий и манипуляций }\end{array}$ \\
\hline Методы управления процессом обучения & Централизованное & Студентоцентрированное \\
\hline Методы обучения & $\begin{array}{l}\text { Информационно-иллюстрированные методы, ре- } \\
\text { продуктивная деятельность, лекции, бесед. }\end{array}$ & $\begin{array}{l}\text { Все методы связаны с выполнением деятельности - } \\
\text { практических задач (проблемный, деятельностный. } \\
\text { практико - ориентированный, компетентностный } \\
\text { подходы) }\end{array}$ \\
\hline Оборудование & $\begin{array}{l}\text { Бумажные, электронные учебники, мультимедий- } \\
\text { ная наглядность, компьютерная техника }\end{array}$ & $\begin{array}{l}\text { Цифровые устройства создают реальную профессио- } \\
\text { нальную среду }\end{array}$ \\
\hline Уровень свободы действий & $\begin{array}{l}\text { Занятия и определенные виды работ ограничены по } \\
\text { времени, определенном преподавателем }\end{array}$ & $\begin{array}{l}\text { Большая свобода приспособления времени занятий } \\
\text { к индивидуальным потребностям, неограниченное } \\
\text { количество тренировок }\end{array}$ \\
\hline Темп обучения & $\begin{array}{l}\text { Все проходят изучение в одном темпе, определен- } \\
\text { ным календарным планом }\end{array}$ & $\begin{array}{l}\text { Каждый студент может учиться в собственном тем- } \\
\text { пе, в зависимости от выполнения поставленных } \\
\text { задач и индивидууально - психических качеств сту- } \\
\text { дентов. }\end{array}$ \\
\hline Темп обучения & $\begin{array}{l}\text { Все проходят изучение в одном темпе, определен- } \\
\text { ным календарным планом }\end{array}$ & $\begin{array}{l}\text { Каждый студент может учиться в собственном тем- } \\
\text { пе, в зависимости от выполнения поставленных за- } \\
\text { дач и индивидууально - психических качеств студен- } \\
\text { тов. }\end{array}$ \\
\hline Уровень контроля за процессом обучения & $\begin{array}{l}\text { Формальные, не индивидуализированные формы } \\
\text { контроля }\end{array}$ & $\begin{array}{l}\text { Гибкие, индивидуализированные формы контроля с } \\
\text { обязательной рефлексией и самоконтролем }\end{array}$ \\
\hline Результат обучения & Совокупность знаний, умений и навыков & $\begin{array}{l}\text { Формирование профессиональных компетентностей } \\
\text { - умение использовать полученные знания на прак- } \\
\text { тике }\end{array}$ \\
\hline
\end{tabular}

использоваться при обучении всех студентов клинических кафедр и врачей-интернов на практических занятиях в центре симуляционного обучения, где проводится воспроизведение клинической ситуации согласно каждой теме и цели занятия перед встречей с реальным пациентом.

При каждом медицинском университете целесообразно внедрить такие практически ориентированные комнаты: зал сердечно-легочной реанимации; центр экстренной медицинской помощи; зал медицинских манипуляций; гинекологический центр; родильный зал; пе- диатрический зал; лечебный центр; хирургический зал; стоматологический зал; зал виртуального симуляционного обучения; стерилизационная.

В предлагаемой модели центра симуляционного обучения при каждом университете также важно организовать кабинет руководителя Центра, преподавательскую, лаборантскую, комнаты для оборудования и расходных материалов и несколько дебрифинг-залов. По нашему мнению, чрезвычайно важной и ответственной частью симуляционного обучения является дебрифинг, то есть обсуждение с преподавателем после выполнения сце- 
нариев, которые проводятся в соответствующих комнатах. Для дебрифинга используют определенный набор методик и правил, перечень вопросов и так далее. Во время дебрифинга преподаватели вместе со студентами или врачами-интернами просматривают и анализируют видеозаписи действий команды, обращая внимание не только на технику исполнения, но и на различные моменты, связанные с техническими навыками - коммуникацию и взаимодействие в команде, процесс принятия решений, роль лидера, распределение задач, эффективностью участия всех членов команды и др. [3].

Преподаватели и студенты совместно определяют успехи и положительные стороны, ключевые проблемы и приходят к выводу, что именно нужно изменить, чтобы команда и каждый отдельно взятый учащийся работали лучше и эффективнее. Проведение дебрифингов - это тема, которой нужно уделять особое внимание, эффективные методики дебрифинга существенно повышают пользу от проведенного обучения.

Симуляционная форма обучения является наиболее оптимальной при оказании экстренной и неотложной медицинской помощи при отработке сценариев в зале экстренной медицинской помощи и зале сердечно-легочной реанимации. Именно в этом случае возможно полно и реалистично моделировать объект в определенной ситуации, получить необходимые теоретические и практические знания, отработать конкретные навыки, не нанося вреда здоровью человека. В зале сердечнолегочной реанимации целесообразно проводить отработку навыков обеспечения проходимости верхних дыхательных путей различными методами, технику искусственной вентиляции легких, базовые реанимационные мероприятия (техника выполнения непрямого массажа сердца и искусственной вентиляции легких) с использованием автоматического дефибриллятора, распознавание сердечных ритмов. В зале экстренной медицинской помощи необходимо отрабатывать навыки первичного обследования пострадавшего, распознавания уровня сознания, техники вторичного обследования пострадавшего, техники перемещения пострадавшего с помощью твердых и мягких носилок, техники остановки наружного кровотечения, техники наложение клапанной повязки при напряженном пневмотораксе, техники иммобилизации верхней и нижней конечностей, техники применение шейного воротника и др.

В зале медицинских манипуляций необходимо поставить тренажеры, которые позволяют провести отработку навыков внутримышечных, внутривенных, подкожных, внутрикожных инъекций. Тренажеры в виде руки взрослого и ребенка с реалистичной венозной сетью позволят наработать технику постановки венозного порта с налаживанием внутривенной инфузии через систему для внутривенных вливаний, а также проведение забо- ра крови для исследования. Реалистичности придает использование в симуляторах имитированной крови.

В родильном зале целесообразно установить функциональные манекены, позволяющие усвоить необходимые практические манипуляции по акушерству (приемы Леопольда, наружный массаж матки, ручное отделение и удаление последа, наложение акушерских щипцов и вакуум-экстрактора). Реалистичный симулятор в виде женщины позволяет освоить такие практические навыки, как: пальпация молочных желез, определение степени раскрытия шейки матки, выслушивание звуков сердца плода, воспроизводство различных вариантов расположения плаценты, наложение влагалищных швов. В гинекологическом зале может присутствовать элементарная модель для обучения методам гинекологического обследования, что позволит приобрести практические навыки в диагностических гинекологических процедурах путем исследования анатомических структур, пальпации брюшной полости, введения расширителей и зеркал. Данный тренажер позволит проводить различные гинекологические исследования: осмотр влагалища и влагалищной части шейки матки в зеркалах; бимануальное исследование; оценку различных положений матки; зондирование матки; введение и удаление внутриматочного контрацептива.

Манекен, который имитирует годовалого ребенка с подвижными руками, ножками и головой должен находиться в педиатрическом зале, что позволит проводить основные и более сложные педиатрические процедуры, такие как купание и перевязка, глазные процедуры, гигиена полости рта и зубов (подвижная челюсть с зубами и языком), кормление через трубку и промывание желудка, внутримышечные инъекции (бедро), трахеотомия, введение катетера девочкам и мальчикам, постановка клизмы. В данной комнате целесообразно установить компьютеризированные тренажеры, позволяющие отработать навыки обследования сердечно-сосудистой системы с электрокардиографическим контролем, а также дыхательной системы с имитацией различных ситуаций в педиатрии.

Кабинет симуляционного обучения для целей кафедры внутренних болезней должен быть оснащен манекеном в виде торса реального пациента для аускультации и перкуссии при различных патологиях органов дыхания и сердца. Инструктор выбирает одно из сердечных и легочных состояний с помощью дистанционного управления. Также кабинет содержит манекен, имитирующий нарушения сердечного ритма с кардиомониторингом, который дает возможность инструктору дистанционно управлять и изменять сердечные ритмы. Кабинет оборудован электрокардиографом с возможностью в реальном времени отработать навык снятия кардиограммы на студенте-волонтере. 
Дополнительно целесообразно установить тренажеры с разнообразными патологиями сетчатки глаза и уха. Для кафедры стоматологии обязательно наличие манекенов головы с полной имитацией мягких и твёрдых тканей челюстно-лицевой области.

В хирургическом зале следует поместить виртуальную операционную, где проводится изучение принципов работы операционной и предоперационной комнат, с последующей возможностью отработки навыков обработки рук хирурга, одевания стерильного халата и перчаток, обработки и обкладки операционного поля. Для студентов курса травматологии комната должна содержать разнообразные реалистичные кости тела человека с импровизированными вариантами переломов. Имеющийся хирургический и травматологический инструментарий позволит выполнять наложение аппаратов внешней фиксации. Для занятий по хирургии важно дополнительно оборудовать симулируемую стерилизационную с возможностью проведения подготовки инструментов и хирургического белья к стерилизации, закладки стерилизационных биксов, изучения принципа действия стерилизационных аппаратов. Зал виртуального симуляционного обучения важно оборудовать соответствующим количеством персональных компьютеров для проведения контроля закрепления пройденного материала в виде тестов, а также возможностью проведения симуляционного обучения с помощью компьютерных симуляционных программ.

Выводы. Симуляционные технологии в медицинском образовательном процессе обеспечивают: создание образовательного пространства, которое построено на насущных и актуальных потребностях тех, кто учится; способствование формирования мотивации к дальнейшему самостоятельному и коллективному когнитивному росту; снижение уровня напряженности, снижение эмоционального барьера перед профессиональной деятельностью; реалистичное обучение без риска для человеческой жизни, что позволяет создать искусственные условия, максимально приближенные к реальной профессиональной деятельности; формирование профессионального мышления на высоком мотивированном уровне, развитие творческого мышления и практического умения; развитие навыков системного подхода к решению проблем, время на усвоение материала имеет тенденцию к корреляции с интеллектуальным потенциалом студента; высокую эффективность усвояемости изучаемого материала; повышение качества обучения и формирование профессиональных компетенций; практическую отработку изученных теоретических знаний; возможность многократного повторения манипуляций до достижения автоматизма; возможность осложнения сценариев и действий специфическими «экстренными случаями»; отработку работы в команде, безопасную форму профессионального поведения и навыков общения, механизмов принятия решений в сложных профессиональных ситуациях; адаптацию образовательного процесса; подготовку врача по всем спектрам профессиональных компетенций; возможность объективной оценки уровня сформированных профессиональных компетентностей специалиста; самотестирование полученных знаний и навыков, оценку эффективности собственных действий; уменьшение потребности в учебно-методических пособиях на бумажных носителях; развитие эмпатии и эмоционального интеллекта, что позволяет физически ощутить и пережить опыт.

Снижение уровня стресса позволяет достичь более быстрого освоения навыка, чем при очной тренировке. При этом, субъективно, учащиеся чувствуют себя комфортнее, а физиологически их состояние приближено к реальной жизненной ситуации.

\section{ЛИТЕРАТУРА}

1. Bailenson J. Experience on demand: What virtual reality is, how it works, and what it can do. - WW Norton \& Company, 2018. p.

2. Hopkins L. et al. To the point: medical education, technology, and the millennial learner // American journal of obstetrics and gynecology. 2018. T.218. №.2. P. 188-192.

3. Lai P., Zou W. The application of virtual reality technology in medical education and training //Global Journal of Information Technology: Emerging Technologies. 2018. T.8. №.1. P. 10-15.

4. So H.Y. et al. Simulation in medical education // Journal of the Royal College of Physicians of Edinburgh. 2019. T.49. №.1. P. 52-57.

5. Селиванов В.В. Теория мышления как процесса: экспериментальное подтверждение // Experimental Psychology. 2019. T.12. №.1. С. 40-52. 